\title{
Atomically sculptured heart in oxide film using convergent electron beam
}

\author{
Gwangyeob Lee', Seung-Hyub Baek ${ }^{2}$ and Hye Jung Chang ${ }^{1,3^{*}}$
}

\begin{abstract}
We demonstrate a fabrication of an atomically controlled single-crystal heart-shaped nanostructure using a convergent electron beam in a scanning transmission electron microscope. The delicately controlled e-beam enable epitaxial crystallization of perovskite oxide $\mathrm{LaAlO}_{3}$ grown out of the relative conductive interface (i.e. 2 dimensional electron gas) between amorphous $\mathrm{LaAlO}_{3} /$ crystalline $\mathrm{SrTiO}_{3}$.
\end{abstract}

Keywords: Epitaxial crystallization, Electron beam irradiation, Spherical aberration corrected scanning transmission electron microscope, Nanoarchitectonics

\section{Description}

Lithography techniques utilizing various sources including light, X-rays, electron beams (e-beams), and ion beams have been investigated to obtain better performance (Levenson et al. 1982; Ehrfeld and Lehr 1995; Watt et al. 2005). Among these techniques, e-beam lithography is one of the most promising methods of fabricating nanostructures because of its excellent spatial resolution (Tseng et al. 2003; Altissimo 2010). Atomically controlled nanostructure sculpting can be conducted using recent advances in aberration-corrected scanning transmission electron microscopy (STEM) (Song et al. 2011; Jesse et al. 2015). In this study, we investigated the e-beam controlled epitaxial crystallization of an amorphous $\mathrm{LaAlO}_{3}$ (a-LAO) thin film that had a conductive interface with a $\mathrm{SrTiO}_{3}$ (STO) substrate (Moon et al. 2016).

The a-LAO thin film was grown on $\mathrm{TiO}_{2}$-terminated STO substrates at room temperature by pulsed laser deposition in an oxygen atmosphere. Cross-sectional TEM specimens were prepared by standard mechanical polishing (Struers; Labopol-5) and subsequent argon-ion

\footnotetext{
* Correspondence: almacore@kist.re.kr

${ }^{1}$ Advanced Analysis Center, Korea Institute of Science and Technology, Seoul 02792, Republic of Korea

${ }^{3}$ Division of Nano and Information Technology, KIST School, University of Science and Technology, Seoul 02792, Republic of Korea

Full list of author information is available at the end of the article
}

milling (PIPS 691; Gatan). Observation of the crystallization of the a-LAO under e-beam irradiation was performed using aberration-corrected STEM (Titan S80-300; FEI), and the convergent e-beam was controlled by STEM software. The acceleration voltage and dose rate of the incident e-beam were $300 \mathrm{keV}$ and $0.169 \times 10^{9} \mathrm{e}^{-} \mathrm{A}^{-2} \mathrm{~s}^{-1}$, respectively.

Under delicately controlled e-beam irradiation, the amorphous structure changed into a crystalline structure with epitaxy with the STO substrate. Using this technique, we sculptured heart-shaped crystallized LAO in a-LAO layer (Fig. 1). The atomically controlled nanostructure sculpting was conducted using several control parameters such as the interfacial conductivity, dose rate, and e-beam's distance from the heterointerface (Lee et al. 2017). The heart-shaped crystallized region with a brighter contrast in the high-angle annular darkfield (HAADF) STEM image was perovskite-type pseudocubic LAO, which was confirmed by the chemical composition and diffraction pattern analyses (Lee et al. 2017). We hope that e-beam lithography using sub-nano scale e-beams in STEM can be applied to manipulate the structures and properties of materials and devices.

\section{Springer Open}

(- The Author(s). 2021 Open Access This article is licensed under a Creative Commons Attribution 4.0 International License, which permits use, sharing, adaptation, distribution and reproduction in any medium or format, as long as you give appropriate credit to the original author(s) and the source, provide a link to the Creative Commons licence, and indicate if changes were made. The images or other third party material in this article are included in the article's Creative Commons licence, unless indicated otherwise in a credit line to the material. If material is not included in the article's Creative Commons licence and your intended use is not permitted by statutory regulation or exceeds the permitted use, you will need to obtain permission directly from the copyright holder. To view a copy of this licence, visit http://creativecommons.org/licenses/by/4.0/. 

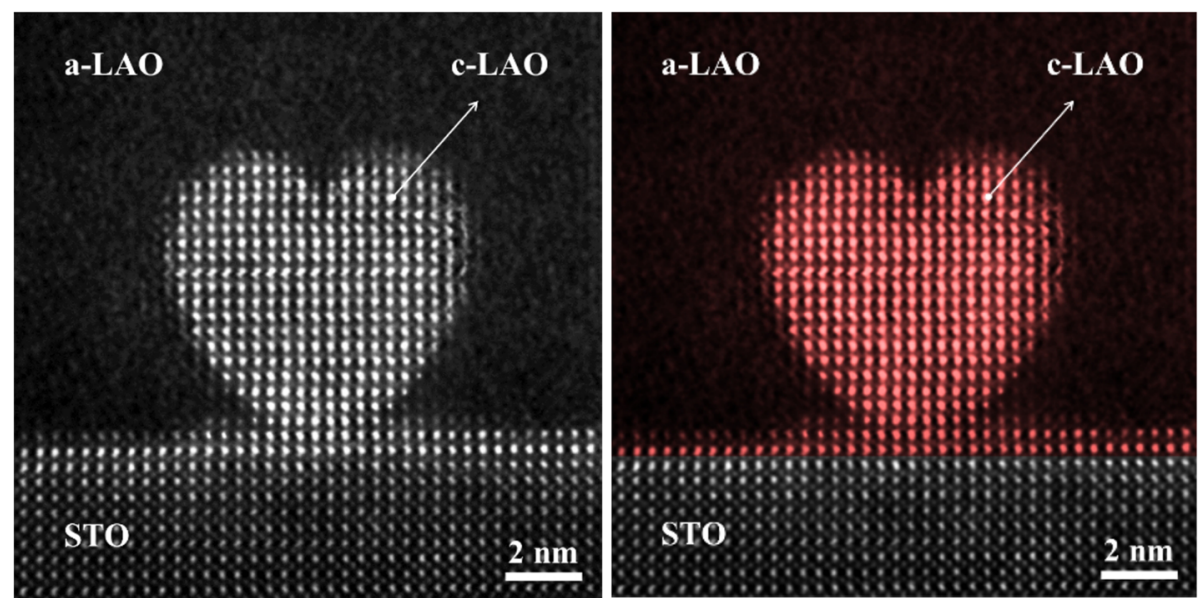

Fig. 1 A high-angle annular dark-field scanning transmission electron microscopy (HAADF STEM) (left) and colored image (right) of the sculptured heart-shaped crystallized LAO in the a-LAO region through e-beam irradiation in STEM

\section{Acknowledgments}

Not applicable.

\section{Authors' contributions}

Hye Jung Chang supervised the project and wrote the manuscript.

Gwangyeob Lee conducted the STEM experiment to generate the data and prepared the manuscript. Seung-Hyub Baek prepared the samples. All the authors discussed the results and approved the final manuscript.

\section{Funding}

This study was supported by the Basic Science Research Program through the National Research Foundation of Korea (NRF) funded by the Ministry of Science, ICT, and Future Planning (2017R1A2B2012514), and the KIST Institutional Program (2 V08170).

\section{Availability of data and materials}

Not applicable.

\section{Competing interests}

The authors declare that they have no competing interests.

\section{Author details}

${ }^{1}$ Advanced Analysis Center, Korea Institute of Science and Technology, Seoul 02792, Republic of Korea. ${ }^{2}$ Electronic Materials Research Center, Korea Institute of Science and Technology, Seoul 02792, Republic of Korea. ${ }^{3}$ Division of Nano and Information Technology, KIST School, University of Science and Technology, Seoul 02792, Republic of Korea.

\section{Received: 12 October 2020 Accepted: 25 December 2020}

Published online: 11 January 2021

\section{References}

M. Altissimo, E-beam lithography for micro-nanofabrication. Biomicrofluidics 4(2), $026503(2010)$

W. Ehrfeld, H. Lehr, Deep X-ray lithography for the production of threedimensional microstructures from metals, polymers and ceramics. Radiat. Phys. Chem. 45(3), 349-365 (1995)

S. Jesse, Q. He, A.R. Lupini, D.N. Leonard, M.P. Oxley, O. Ovchinnikov, et al., Atomic-level sculpting of crystalline oxides: toward bulk nanofabrication with single atomic plane precision. Small 11(44), 5895-5900 (2015)

G. Lee, S.Y. Moon, J. Kim, S.H. Baek, D.H. Kim, H.W. Jang, et al., Electron beam induced epitaxial crystallization in a conducting and insulating a- $\mathrm{LaAlO}_{3} /$ $\mathrm{SrTiO}_{3}$ system. RSC Adv. 7(64), 40279-40285 (2017)

M.D. Levenson, N. Viswanathan, R.A. Simpson, Improving resolution in photolithography with a phase-shifting mask. IEEE Trans. Electron Devices 29(12), 1828-1836 (1982)
S.Y. Moon, C.W. Moon, H.J. Chang, T. Kim, C.-Y. Kang, H.-J. Choi, et al., Comprehensive study on critical role of surface oxygen vacancies for 2DEG formation and annihilation in $\mathrm{LaAlO}_{3} / \mathrm{SrTiO}_{3}$ heterointerfaces. Electron. Mater. Lett. 12(2), 243-250 (2016)

B. Song, G.F. Schneider, Q. Xu, G. Pandraud, C. Dekker, H. Zandbergen, Atomicscale electron-beam sculpting of near-defect-free graphene nanostructures. Nano Lett. 11(6), 2247-2250 (2011)

A.A. Tseng, K. Chen, C.D. Chen, K.J. Ma, Electron beam lithography in nanoscale fabrication: recent development. IEEE Trans. Electron. Packaging Manuf 26(2), 141-149 (2003)

F. Watt, A. Bettiol, J. Van Kan, E. Teo, M. Breese, Ion beam lithography and nanofabrication: a review. Int. J. Nanosci. 4(03), 269-286 (2005)

\section{Publisher's Note}

Springer Nature remains neutral with regard to jurisdictional claims in published maps and institutional affiliations.

\section{Submit your manuscript to a SpringerOpen ${ }^{\mathcal{O}}$ journal and benefit from:}

- Convenient online submission

- Rigorous peer review

- Open access: articles freely available online

- High visibility within the field

- Retaining the copyright to your article

Submit your next manuscript at $\boldsymbol{\nabla}$ springeropen.com 